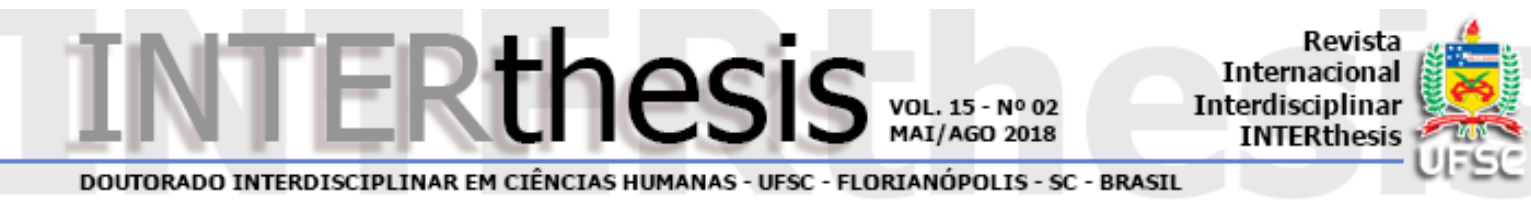

\title{
AS RELAÇÕES DE GÊNEROS E OS SUJEITOS QUE ATUAVAM, ATUAM, NO COMÉRCIO DE DROGAS ILÍCITAS
}

\section{Resumo:}

André Masao Peres Tokuda1 Wiliam Siqueira Peres ${ }^{2}$

Este artigo visa problematizar sobre a interferência das relações de gêneros, especificamente as masculinidades, na busca dos sujeitos pelo comércio de drogas ilícitas. Utilizamos o método cartográfico para mapear as histórias existenciais de oito pessoas que estavam presas, problematizando sobre as experiências vividas por essas até serem condenadas no art. 33 do Código Penal brasileiro. Com os resultados das cartografias pode-se colocar que são múltiplas as linhas que interferem na entrada no comércio de drogas, no entanto as relações de gêneros tiveram destaque, a necessidade de se provar "homem de verdade" foi um dos fatores mais presentes nas falas dos participantes. Assim, discutimos a necessidade da Psicologia se distanciar de posicionamentos limitados, por exemplo, de que as ações infracionais tenham suas causas em patologias, ou somente é uma questão de desigualdade social, sendo mais problematizadora das diversas linhas que atravessam e constroem os sujeitos.

Palavras-chave: Psicologia Social. Comércio de drogas. Masculinidade. Psicologia Jurídica. Gênero e Sexualidade.

\section{INTRODUÇÃO}

Este artigo é resultado de pesquisa de iniciação científica, que teve apoio da Fundação de Amparo à Pesquisa do Estado de São Paulo (FAPESP). Nesse trabalho problematizamos sobre a entrada dos sujeitos no comércio ${ }^{3}$ de drogas ilícitas - cabível de aprisionamento no art. 33 da Lei n. 11.323/06, que instituiu o Sistema Nacional de Políticas Públicas sobre Drogas (Sisnad) - a partir de revisão bibliográfica e de entrevistas realizadas com oito pessoas do sexo masculino que estavam presas em uma unidade penitenciária de regime fechado no estado de São Paulo, sentenciadas com base no artigo citado acima.

\footnotetext{
${ }_{1}$ Doutorando pela Universidade Estadual Paulista "Júlio de Mesquita Filho" em Assis, SP, Brasil. Email: andremasao@hotmail.com

2 Doutor em Saúde Coletiva pela Universidade do Estado do Rio de Janeiro. Pós-Doutorado em Psicologia e Estudos de Gênero pela Universidade de Buenos Aires, Argentina. Professor na Graduação e Pós-graduação em Psicologia da Universidade Estadual Paulista Júlio de Mesquita Filho, em Assis, SP, Brasil E-mail: pereswiliam@gmail.com

${ }^{3}$ Com a leitura de "A cidade nas fronteiras do legal e ilegal" de Vera da Silva Telles (2010), acreditamos que a utilização do termo comércio de drogas ilícitas fica mais apropriado do que tráfico, pois partimos do pressuposto que apesar de ser considerada uma atividade ilícita, é vista como um trabalho, muitas vezes ficando no imaginário de algumas pessoas como uma pequena ilegalidade, um bico contra o desemprego e trabalhos mal pagos.
} 
De início, vale colocar a importância de artigos e pesquisas neste campo, devido ao fato de parte da população viver, atualmente, com sentimentos de insegurança e medo, em decorrência das notícias sobre as altas taxas de crimes que são vinculadas pela "mass media", essa também ajuda no processo de criminalização das pessoas de baixa renda, pois em sua grande maioria as notícias apontam territórios ocupados por essa população como de alta periculosidade, ou são colocados como "berço da criminalidade", não problematizando a desigualdade econômica e social e as estruturas de gêneros e sexualidades existentes em nosso país, sendo variáveis importantes para o cometimentos de crimes e atos de violência.

$\mathrm{O}$ medo e a violência estão presentes em todas as classes sociais e econômicas, seja pelo receio da violência cometida por assaltantes, que é explorado pela "mass media", ou, em muitos casos (principalmente na classe pobre e com pessoas negras), temor com a violência das instituições do Estado (polícia), que são poucos ou quase não mostrados em emissoras de televisão, ou jornais (FEFFERMANN, 2006; FIORELLI; MANGINI, 2012; 2008; LIMA, 2009).

Assim, a partir dessas discussões buscamos problematizar o que pode levar o sujeito ao comércio de drogas, iniciando o projeto de pesquisa pela revisão bibliográfica. Deste modo, podemos apontar que muitas hipóteses foram e são criadas sobre o cometimento de atos criminais, nos quais diversos parâmetros são apontados: biológicos (o fator genético, neurológico, bioquímico e psicofisiológicos), psicológicos e sociais, que para alguns pesquisadores é somente uma característica da sociedade contemporânea (GARLAND, 2008; SERAFIM, 2003). Feffermann aponta que:

As razões e forma de ingresso no tráfico de drogas são numerosas e estão relacionadas também com as histórias individuais destes jovens. O fato é que o tráfico é uma oferta cotidiana a estes jovens, a escolha disponível. (2006, p. 237).

Segundo Feffermann (2006), muitos sujeitos e o próprio Estado apontam as famílias como os grandes culpados pelo o aumento da violência, criando a ideia de "famílias desestruturadas", servindo apenas como forma de estigmatizar composições familiares que fogem da ideia da burguesia, de "família nuclear" e "família normal".

Por outro lado, Jean Bergeret (1990) apresenta a teoria da "violência fundamental", tomando-a como pulsão que gera energia, ela é canalizada pelas pulsões libidinais para objetos e objetivos definidos (o que se aproxima com a teoria de Freud (1996) sobre a sexualidade, na qual aponta que exista um desvio das energias sexuais das metas sexuais). De acordo com essa leitura, quando tal energia 
não é integrada à libido, se torna perversa, e se a relação entre a criança e os pais continua com a marca da rivalidade, pode fazer com que a mesma não se oriente pelo amor, e suas respostas tendem a se limitar ao ato (respostas irracionais). O crime seria então a expressão de conflitos intra-individuais, uma forma utilizada para romper com a dominação, o objetivo seria a descarga de tensões e frustrações.

Quando o conflito fundamental é satisfatoriamente resolvido, as respostas da criança são mais reflexivas, nesse caso, o crime seria expressão de conflitos interindividuais e seu objetivo construtivo (BERGERET, 1990). O sujeito utiliza o ato infracional para atingir determinados fins, por exemplo: o bem estar (BERGERET, 1990). A partir desta teoria, embora reducionista (criminalizando somente os sujeitos), pode supor-se que este tem uma inabilidade na solução dos conflitos oriundos do convívio com grande parte da sociedade, com a cultura num contexto em que se reeditam as relações de domínio, poder e exclusão de certos direitos.

Esta inabilidade pode ter começado, predominantemente, de toda uma história de marginalização psíquica e social da qual o sujeito foi vítima, ou seja, pode ter sido criminalizado pelas normas seletivas da sociedade (ROCHA, 1994). Pensando assim, a população prisional seria, em sua maioria, composta por sujeitos para quem todas as oportunidades socialmente criadas, como educação e trabalho, falharam (FOUCAULT, 1997; ROCHA, 1994;).

Pode-se colocar que são inúmeras as teorias e variáveis apontadas para que os sujeitos cometam algum delito. Pretendemos agora problematizar com nosso olhar, através das entrevistas, a entrada dos sujeitos no comércio de drogas ilícitas, procurando não sermos reducionistas.

\section{MÉTODO}

A pesquisa foi desenvolvida em uma penitenciária de regime fechado do estado de São Paulo, através de entrevistas com oito sujeitos do sexo de macho, gênero masculino, ou seja, todos cisgêneros, com a idade entre 25 e 53 anos, que estavam condenados no artigo 33 da Lei n. 11.343 (BRASIL, 2006). A escolha da faixa etária deu-se por conta da possibilidade de comparar épocas e relacioná-las com possíveis manifestações históricas, da ordem política, cultural e social brasileira.

A abordagem foi realizada nos locais destinados para atendimentos das psicólogas, assistentes sociais, advogados(as) e enfermeiros(as), e também na sala 
do diretor da unidade e do diretor de segurança e disciplina, que é utilizada para atendimentos aos sentenciados. Essa mudança ocorreu devido ao fato de ser uma sala mais silenciosa. Os sujeitos foram esclarecidos sobre os objetivos do estudo, para então serem convidados a falarem sobre suas histórias de vida, em entrevistas que foram gravadas.

As entrevistas foram norteadas através de tópicos disparadores contendo os seguintes itens: processos de vida (infância, adolescência e adultez), passagens criminais (entrada e permanência no "mundo do crime"), interação com a sociedade fora da penitenciária (reinserção social e laboral junto às instituições sociais), relações familiares, relação com outros sentenciados (socialização), vivência em uma penitenciária (cumprimento de normas), vivência no comércio de drogas ilícitas (função ocupada no sistema do comércio), visão do entrevistado sobre o uso de drogas ilícitas e penitenciárias de regime fechado e perspectivas futuras (projetos de vida).

Apostamos que os estudos problematizadores dos motivos que levam os sujeitos ao cometimento de delitos, no caso desta pesquisa o comércio de drogas ilícitas, exige a presença de uma abordagem teórica que inclua variações, cuidando para não ser reducionista e acreditando que cada sujeito está sempre em construção permanente, assim a vida é vista como processo.

Desta forma o método cartográfico, criado por Deleuze e Guattari (1995), foi o que melhor respondeu as às nossas exigências e foi tomado como norteador dos procedimentos. A cartografia tem como objetivo acompanhar processos de produção e não representar um objeto. Seguindo essa perspectiva, em nenhum momento tivemos preocupações com a busca de verdades, ou de construção de regimes de verdades fechados e absolutos, nem tão pouco queríamos estabelecer modelos prontos.

Para análise dos dados coletados efetuamos a relação entre esses e o referencial teórico, buscando problematizar as variáveis apresentadas que levaram os sujeitos a entrarem para o comércio de drogas ilícitas, levando em consideração os inúmeros fatores que podem influenciar tais relações (desigualdades sociais, políticas e culturais, ausência de políticas públicas que deem garantias de cidadania), em especial neste artigo focamos na discussão da construção das masculinidades como um dos fatores para a ilegalidade. 
Vale ressaltar, que essa pesquisa de iniciação cientifica foi aprovada por Comitê de Ética em Pesquisa. Tivemos dificuldades, como as encontradas por Dias (2011), com o comitê em relação a alguns discursos e teorias utilizadas, que foram questionadas, no entanto com as justificativas feitas o trabalho pôde ser aprovado4. Durante as entrevistas ficamos em uma sala com os participantes, nenhum agente penitenciário foi designado para acompanha-los durante as entrevistas, o que é padrão em pesquisas nessa área, acreditamos que estes procedimentos foram tomados devido termos feito estágio extracurricular na unidade e assim estarmos familiarizados com todos que lá estavam (funcionários e pessoas encarceradas).

\section{RESULTADOS E DISCUSSÕES}

Baseados no conceito de rizoma (o termo é "emprestado" por Deleuze e Guattari (1995, p. 32) da botânica, contrapondo-se à ideia de raiz (algo fixo), sendo definido pelos feixes de linhas que compõe verdadeiras redes sem um eixo principal, não tendo começo nem fim, mas sempre um meio pelo qual cresce e transborda) e no método cartográfico, entendemos que seríamos reducionistas e presunçosos ao colocarmos uma ou outra linha como causadoras dessas pessoas entrevistadas atuarem junto ao comércio de drogas (DELEUZE; GUATTARI, 1995). Desta forma, afirmamos que devemos nos posicionar de forma crítica e problematizadora perante os motivos que levam esses sujeitos a agirem no comércio de drogas, acreditando que assim estaremos implicados com os processos desejantes e de subjetivação.

Apontamos no inicio do trabalho diversas teorias que foram sendo construídas sobre o cometimento de delitos. No entanto na literatura consultada nenhum dos autores problematizam questões sobre as masculinidades como uma das variáveis que podem contribuir como fator que levam os sujeitos a traficar. Ou seja, as construções das masculinidades não são utilizadas como categorias de análises para essa área, as questões de gêneros são discutidas, principalmente, quando se trata de

\footnotetext{
${ }^{4}$ Em um primeiro momento utilizamos no título do projeto "Vidas infames: um olhar sobre os sujeitos do tráfico" e foi alterado para "Olhares possíveis sobre os sujeitos do tráfico em situação prisional". Esta mudança foi feita por ter sido um pedido do parecerista do Comitê de Ética em Pesquisa da Secretaria da Administração Penitenciária (SAP), pois o mesmo fazia a leitura que "infames" seria depreciativo, no entanto discutimos o conceito a partir de leituras da obra de Foucault, no qual trata de infame pessoas que tornam-se invisíveis para a população, caso de pessoas que estão presas. Apesar de acreditarmos que não havia uma questão ética, decidimos por alterar o título para que o projeto fosse aprovado e não houvesse atrasos na pesquisa.
} 
violência doméstica, contra a mulher, ou quando se discute a presença feminina no cometimento de atos ilícitos, como nas pesquisas de De Souza (2009) e Barcinski (2009).

Toda via, a partir de nosso referencial teórico e das entrevistas realizadas com os sentenciados, acreditamos que as definições do que é ser homem em nossa sociedade tem grande importância quando se pensa nos motivos da entrada para o "mundo do crime". Desta forma queremos problematizar sobre as construções dos masculinos, as múltiplas linhas que atravessam os sujeitos e que os definem como homens, isto é, entendemos que as masculinidades e gêneros são sempre construídos em contextos bem definidos por jogos de poderes e regimes de verdades, e que são importantes categorias de análise da realidade social.

Assim, partimos da ideia que as construções dos masculinos, segundo Georges Daniel Janja Bloc Boris (2011), são constituições subjetivas, ou seja, se desenvolvem de maneira individual e particularizada. No entanto, cabe ressaltar que existem aspectos comuns, assim como diferenças, entre homens de uma mesma cultura, classe econômica e raça, portanto se questiona aqui a ideia de "identidade masculina", como algo fechado, cristalizado e universal.

A noção de identidade pressupõe uma relação de semelhança com determinado modelo que é imposto, seja pela família ou sociedade, esquece-se que possa existir as mais variadas diferenciações e se nega os diversos tipos de masculinidades (BORIS, 2011). Desta forma concordamos com o pensamento de Maria Rita Kehl (1996, p. 11-12):

[...] nada poderia parecer mais consoante com a idéia de diferença do que a perspectiva de que cada sujeito possa se dizer um, num contexto em que tudo se massifica, se industrializa, se globaliza. No entanto, quando se fala em diferença, a referência não são as singulares e sim a produção de identidades. [...] As identidades são as próteses subjetivas produzidas nas sociedades de massa [...] um dos modos contemporâneos de alienação.

A noção de identidade pressupõe uma semelhança com algo que é imposto como igual (nasce com pênis tem que ser do gênero masculino e ter todos comportamentos característicos dessa população), opondo-se à ideia de diferença, desta forma criando sujeitos não pensantes, alienados, até e principalmente em seus desejos, ou seja, uma imposição de como se deve "ser" em sua existência, como consequência dos efeitos da biopolítica e do biopoder apontados por Foucault (1988), que disciplina os corpos e regula as populações. 
$\mathrm{Na}$ tentativa de conceituação deparamo-nos com a concepção de masculinidades como sendo constituídas por diversos atributos e atitudes que são esperados dos homens em diferentes contextos culturais, ou seja, traços normatizadores e cristalizadores, que definem práticas sociais do que é ser "homem", criando-se assim, o que Robert Connell (1995) chamou de "masculinidade hegemônica", definida como um conjunto de práticas e valores com a função de garantir a posição dominante dos homens e a subordinação das mulheres. Assim como, manter protegido e sempre acionado o sistema de privilégios que garantem poder e superioridade ao homem branco, de classe média, heterossexual, viril, procriador, cristão e impenetrável. Da mesma forma, manter as mulheres em esquemas de submissão e desvalorização de si mesmas, de modo a contribuir para a supervalorização dos modelos ditados pelos homens de como devem se portar diante do mundo, do mundo dos homens.

Essas desigualdades são dadas como molares desde a infância, produzindo crenças de que os homens são superiores e diferentes das mulheres, evidenciados através de biopolíticas e biopoderes regulatórias presentes no sistema sexo/gênero/desejo/práticas sexuais, produzindo sexismos, machismos, misoginias e homofobias (BUTLER, 2003).

Tais ideias são apresentadas desde cedo, pois a educação dos meninos produz a ideia de masculinidade, ou de masculino, que determinam que para ser homem deve-se combater os aspectos que podem ser associados às mulheres, além de aprenderem a estar com os homens, aceitar a lei dos maiores e mais velhos e os ritos que se traduzem em operadores hierárquicos.

Isto se assemelha com a fala de Boris (2011) para quem as diferenças encontradas entre grupos de meninos e de meninas se constroem nas formas de socialização da criança segundo seu sexo a partir do nascimento, e os desdobramentos das fixações das expressões do gênero, o que varia muito por causa dos diferentes cuidadores, mas explica a diversidade das experiências humanas.

Acreditamos como coloca Simone de Beauvoir (1980) que a mulher não nasce mulher, mas se "constrói" como mulher. O mesmo deve-se aplicar ao homem, com isso o mesmo não nasce homem, torna-se. Ou seja, o ser humano não é predeterminado, ou determinado biologicamente, mas construído socialmente através de negociações políticas, assim como- seus desejos, subjetividade e diferenças. As características do masculino e do feminino estão sempre em mudança, em construção 
permanente, inseridos em contextos sociais, históricos e culturais diversos. Desta forma, não sendo apenas vinculada a uma única possibilidade de ser "homem", possibilita-nos pensar em "masculinidades", fugindo ao enquadramento da "masculinidade hegemônica", a qual torna-se despontecioalizadora e limita as possibilidades de ser e estar no mundo (CONNELL, 1995).

Cabe colocar que a noção de gênero, se difere da noção de sexo, pois não se refere e reduz aos órgãos genitais, tão pouco ao mero exercício da prática sexual, mas nos remete aos modos pelas quais os sexos são significados pelo contexto social, político e cultural e suas atribuições de masculinidades e feminilidades. As composições das masculinidades e feminilidades se processariam através dos discursos que se materializam sobre os corpos e os organizam em categorias determinantes das identidades, e em especial, a identidade de gênero (BUTLER, 2003).

Apostamos na crença de que os gêneros são construídos nas relações sociais, a partir de negociações políticas que indicam lugares e comportamentos relativos ao que é ser homem e mulher. Essas marcas/estereótipos colocam em funcionamento diversas tecnologias que funcionam como máquinas binárias e universalizantes de produção dos modos de sensações, pensamentos, desejos, atitudes, comportamentos, relações, valores, estereótipos, conceitos e preconceitos, discursos e práticas dos sujeitos, nos quais são apoiados por instituições centralizadas pelo Estado, e outras instituições reguladoras como a família, escola, igreja e prisão (BORIS, 2011; LAURETIS, 1994).

O gênero é nossa identidade primeira, aquilo que nos qualifica para a vida na cultura, política e sociedade. Esta referência nos permite problematizar os binarismos de modo crítico, evitando respostas prontas e cristalizadas, nos ajudando a sair da ideia de que para ser homem você precisa vestir a máscara de que "homem não chora" (BORIS, 2011; LAURETIS, 1994).

Desta forma a masculinidade começa a ser vista não mais como uma essência, mas como uma linha de pensamento, que é utilizada para justificar a dominação masculina, ou seja, se mantém para que exista o poder do homem sobre a mulher, e, como nos coloca Foucault (1988): o poder cria o sujeito dominado, para assim manter seu poder.

$\mathrm{Na}$ pesquisa realizada com sujeitos do comércio em situação prisional buscamos olhar, mais atentamente, para as expressões de masculinidades que nos 
eram apresentadas através dos discursos e cenas relatadas, vale destacar, em contextos bem demarcados por exercícios de rivalidades e confrontos de forças "entre machos", "sobre machos", que garantiam a sobrevivência e o privilégio de deter o poder, dentro do presídio, sobre os outros presidiários; dupla penalidade: do estado sobre seu corpo enquanto criminoso, do líder da prisão sobre seu corpo enquanto inferioridade e submissão.

Dentro das penitenciárias existe uma maior pressão em se afirmar a condição de homem tradicional hegemônico, como apontado pelos entrevistados. Em seus discursos podemos observar uma necessidade, imposta pelo estabelecimento, de se provar ser homem, "Tinha uns que viam e queriam me confrontar, me confrontei com vários" (ARNALDO ${ }^{5}$ ), “[...] eu conheci a penitenciária, a cadeia, a comarca, o CDP, em uma época que tinha que ser homem para conviver lá dentro, pois se não fosse você era menininha, ou você morria [...]." (HENRIQUE6 ${ }^{6}$.

Nestes relatos podemos entender que existe uma necessidade de provar que se é homem através da luta, como colocou Daniel Welzer-Lang (2001), os homens que fogem de lutas, falam demais, ou são mais frágeis, são tratados como "mulherzinhas", pois os mesmos apresentam estereótipos que são reconhecidos e projetados como sendo das mulheres.

Nos discursos que colhemos pôde-se notar que existe um ideal de masculinidade, como exemplo, homem tem que falar grosso, não deve bater em mulher (mas quando se tem a "necessidade" tem o alvará dos outros), não pode falar

\footnotetext{
${ }^{5}$ Arnaldo, nome fictício, tinha 25 anos na época da entrevista, nasceu e morou em uma cidade do interior do Estado de São Paulo, tinha o ensino fundamental completo. A vizinhança, na qual conviveu na infância, era muito violenta, assim sempre conviveu com o comércio de drogas, mortes e brigas. Seus pais trabalhavam, mas passavam dificuldades econômicas e alimentares. Começou a trabalhar com 13 anos como desenhista e tinha o sonho de ser professor de capoeira. Foi preso pela primeira vez com 17 anos e condenado no artigo 121 (homicídio), disse que matou um sujeito que tentou abusar sexualmente de sua irmã, estava drogado, descobriu quem era a pessoa e acabou cometendo este homicídio. Depois foi mais duas vezes preso e condenado, ambas por tráfico de drogas (art. 33).

${ }^{6}$ Henrique, nome fictício, tinha 31 anos quando participou da pesquisa, nasceu no estado de São Paulo, morou também na Bahia e em Minas Gerais. Foi adotado, juntamente com seu irmão, quando criança por uma farmacêutica e um veterinário. Sua família era de classe média alta, se relacionava com pessoas de todas as classes econômicas. Tinha o sonho de ir para Bahia e ter um grupo de pagode famoso, realizou o primeiro. Outro desejo era conhecer seus pais biológicos, para isto gastou muito do dinheiro que ganhou com o comércio de drogas, mas não conseguiu descobrir. Quando completou 18 anos foi preso pela primeira vez por comercializar drogas e condenado a cumprir 23 anos de reclusão, disse que sua condenação foi grande pela quantidade de drogas e pelo nome conhecido, pois muitas vezes os policiais tentaram o prender, mas nunca o pegavam com drogas, tinha advogados e seu tio era vereador.
} 
muito, ou ter qualquer comportamento (estereotipado) que lembre uma mulher, pode ter quantas mulheres desejar, mas tem que sustentá-las.

Toda essa ideia de "homem de verdade" é construída, segundo Welzer-Lang (2001), na "casa-dos-homens", nesta se constroem como homens longe das mulheres (mães, irmãs, entre outras). A instituição penitenciária poderia ser chamada de uma "casa dos homens com grades" (PERES; SANTOS, 2011).

$\mathrm{Na}$ "casa dos homens" os meninos da mesma idade são atravessados por fortes tendências e grandes pressões para viverem disputas, para saber quem é mais homem, tais como comparações quanto ao tamanho do pênis, maratonas de masturbação, excitações coletivas com pornografia, lutas corporais, práticas de esporte, entre outras (WELZER-LANG, 2001). Na penitenciária também há disputas para saber quem é mais "macho", melhor que outro. Assim, tem-se disputas de futebol, por celas, espaço para ser monitor na escola e também para poder trabalhar na penitenciária. Também existem grandes rivalidades entre as facções pelo comando das penitenciárias.

Os professores são "grandes homens" (homens mais velhos), que vão dos pais aos atores de novelas. São nestas pessoas que os meninos irão se espelhar, desta forma começam a imitar os comportamentos e falas (WELZER-LANG, 2001). Na penitenciária pudemos perceber, através dos discursos, que existe também este ritual, no qual o sentenciado que passou mais tempo preso acaba passando para os mais novos tanto sobre sua experiência no crime, como o que aprendeu e viveu na penitenciária, ensinando as regras de conduta e muitas vezes aconselhando os mais novos a saírem da "vida do crime":

[...] então vivo uma vida de igualdade, procuro passar o que eu passei em cadeia, que já venho tirando uns dias também, só nessa penitenciária aqui, tô indo pra 13. Tirei 12 anos o ano passado aqui, fora as comarcas, então a gente já viu muita covardia, o mais forte matando o mais fraco, destruindo assim, a possibilidade do mais fraco alcançar o objetivo, então você vê muita covardia. Então é que eu faço o máximo, chega um novato, jovenzinho, ensino pra ele o que deve e o que não deve, para amanhã não tá aí correndo na cadeia, podendo até nego tirar a vida dele, mas é o que a gente tem que fazer, ajudar. (JULIANO ${ }^{7}$ )

\footnotetext{
7 Juliano, nome fictício, tinha 53 anos na época da pesquisa, nasceu e morou no interior paulista. Foi criado somente pela mãe e não conheceu o pai biológico. Durante a infância passou por necessidades econômicas (precisou pedir comida), então com nove anos tinha que trabalhar na roça, deixando, muitas vezes, a escola de lado. Sempre teve muitos amigos e esses amigos o levaram a cometer delitos e usar drogas, com 15 anos começou a usar maconha. Estudou até a quarta série do ensino fundamental, mas na penitenciária conseguiu completar o ensino fundamental e atualmente cursa o primeiro ano do ensino médio. Não conseguia arrumar emprego na roça e nem como pedreiro, então começou a vender somente maconha, pois é contra as "drogas químicas" (cocaína, crack, entre outras).
} 
Assim temos uma passagem de conhecimento, entre aquele mais experiente em matéria de penitenciária, e os mais novos. Esta troca de informações acaba ajudando que se mantenha uma penitenciária em ordem e que um grupo, que impôs as regras, não seja questionado. Se têm sujeitos dóceis e úteis, como faz o governo, através do biopoder e biopolítica com as pessoas fora da penitenciaria, ações parecidas se mostram presentes no cotidiano prisional (FOUCAULT, 1988).

Neste sentido, acreditamos que dentro dos presídios paulistas existem as "casas dos homens", que são uma das linhas que compõem a construção da subjetividade masculina, como apontou Boris (2011), assim como há certo modelo de família, sociedade, cultura, entre outras que irá influenciar diretamente na constituição "do homem", e indiretamente "da mulher".

Assim acreditamos que os modos de construções das masculinidades - ainda fortemente determinadas pela ideia normatizadora de que homem de verdade é aquele que sustenta a família, é esperto, agressivo e precisa se situar em posição de superioridades - corroboraram na entrada destes homens (entrevistados) no comércio de drogas ilícitas. No entanto, reforçamos que não estamos falando apenas destes sentenciados, e sim de um grupo de sujeitos que caíram na armadilha das linhas duras, normatizadoras, demarcando a construção de um tipo de masculinidade especifica desse contexto tráfico-penitenciária. Mas cabe colocar que em cada sujeito preso pelo exercício do comércio ilícito pode haver múltiplas linhas que os compunham até este momento, esclarecendo de uma vez por todas que esse sujeito não se reduz apenas a essa marca identitária, mas por devires outros que pedem passagem para sua efetivação. Se esse sujeito é traficante e/ou presidiário, certamente isso não é tudo o que é.

Em sua pesquisa Boris (2011) encontrou que o trabalho é uma das linhas significativas apontada pelos homens como o que compõem o sujeito masculino. $O$ trabalho profissional tem um importante significado para a construção do masculino. Ter um emprego que garanta o sustento da família é uma das principais bases de sustentação da subjetividade e da condição de ser homem, mesmo que este não seja bem remunerado e com péssimas condições de trabalho.

Foi preso pela primeira vez quando tinha 17 anos, por roubo e disse que foi "molecagem", pois pegaram um rádio que estava no quintal de uma casa, a polícia os levou e ficou preso por quase um mês. 
Podemos problematizar, através das entrevistas, que muitos sentenciados acabam buscando o comércio de drogas como uma alternativa de conseguir emprego e dinheiro, assim não precisando depender de suas esposas e/ou familiares. O Entrevistado VII nos traz sua entrada como uma não aceitação de sua dependência econômica:

[...] na realidade não precisava mais fazer isso, porque minha esposa tava trabalhando, mantendo a casa, era para ter um pouco de paciência, ter arrumado um serviço, mas eu fui, pensei, peguei um negócio para vender, foi um dia que a polícia foi em casa e pegou eu lá com droga, aí fui preso, mas não tinha necessidade de estar vendendo, porque minha esposa tava trabalhando e fome nós não estávamos passando, ela mantinha a casa, era só eu ter paciência e arrumar um serviço.

Assim como este entrevistado, outros sentenciados acabam buscando o comércio de drogas como meio para sustentar e dar uma vida melhor à família, respondendo aos estereótipos de gênero masculino de responsabilidade pela prole. Nas entrevistas coletadas existe apontamentos de sujeitos que entraram para o crime como uma possibilidade de ajudar a família, como aponta Arnaldo: "[...] eu entrei para o tráfico em cima da minha necessidade, da minha dificuldade de ter o mantimento, de abrir o armário e não ter o mantimento".

Neste relato pode-se cartografar que o sujeito III sendo considerado "o homem da família" acreditou que deveria a prover economicamente. Em outro relato, Juliano, coloca que sua entrada se baseou em seu pensamento de dar algo melhor para família, mesmo sua mulher trabalhando e não sendo a favor que traficasse:

[...] droga nunca foi aceito, conviveu com dinheiro errado que eu arrumava com o tráfico, mas nunca foi aceito, sempre tinha, também, o serviço deles, a mulher era boa cozinheira, [...] eu pretendia tratar a família. Eu via aquele maior sufoco, necessidade, mó falta de comida em casa, a mentalidade da gente já vem daí, você quer comer comida".

Assim pode ser mapeada a necessidade de afirmação do modelo hegemônico de masculinidade e manutenção de status de "homem de verdade" diante da comunidade e de si mesmo; como colocou Boris (2011), o homem precisa trabalhar e ser o provedor da família, tendo esta ideia afirmada a todo instante em grande parte de nossa sociedade. Em outro relato, Arnaldo, coloca que sua primeira vez na prisão foi devido a um assassinato, segundo o mesmo:

Foi uma situação que aconteceu na minha vida que me abalou, entendeu? Foi uma situação que aconteceu com minha irmã e eu cobrei, aí aconteceu o que aconteceu e eu fui pra FEBEM. Por ser minha irmã eu defendi, o que eu não queria pros outros, eu não queria acontecendo com minha irmã, então à única defesa que vi pra defender ela, foi da forma que ter que fazer isso. [...] ele tentou abusar dela, só que não conseguiu. Aí um dia tava bastante 
drogado e fiquei meio, sou apegado com minha família, com minhas irmãs, entendeu? Aí eu fui, por ela saber quem que era, eu fui e cobrei.

Mais uma vez como "homem ideal da família", o entrevistado, fez o que para muitos é esperado, não deixou que a honra de sua irmã e família fossem manchadas. Desta forma podemos compreender que existe na construção da subjetividade masculina, grande apelo em cuidar, proteger a família e a honra de tudo e todos, podendo ser de forma violenta e agressiva, até mesmo contra pessoas que fazem parte deste grupo, ou seja, a violência contra a mulher e a transformação desta como submissa, muitas vezes parte-se da ideia de estar protegendo a família, a mulher e sua honra, pois tem-se o pensamento de que a mulher enquanto submissa irá cuidar do lar e da família, ideia vendida nos dizeres "mulher para casar" e "moça de família", comumente usados em nossa sociedade.

Assim, pensamos que a sociedade e suas instituições (escola, famílias, entre outras), o Estado e principalmente a Psicologia deva pensar em problematizar questões de gêneros que estão impostas, cristalizadas, normatizadas e fechadas. Enquanto permanecermos com estes pensamentos cristalizados pelos binarismos e universais, muitas subjetividades serão reduzidas a padrões normativos de gêneros, assim homens e mulheres têm suas vidas direcionadas para o comércio, pois os primeiros terão como objetivo não deixar de serem os provedores da família e muitas mulheres poderão acabar se envolvendo para não perderem o posto de "esposa dedicada".

Acreditamos que são diversas as variáveis que compõem a entrada do sujeito no comércio de drogas ilícitas, no entanto muitas vezes se esquecem de se problematizar na perspectiva de gêneros, desta forma acaba se tendo leituras reducionistas.

Ao invés de pensarmos em masculinidade hegemônica com contornos bem definidos, limitados e fechados em si, entendemos que há cruzamentos de múltiplos componentes de subjetivação que se ligam, desligam e religam, influenciando as construções das subjetividades dos sujeitos, se opondo ao modelo binário, assim nos permitindo falar de diversas masculinidades. Vale ressaltar que quando problematizamos as masculinidades, também, estamos ao mesmo tempo discutindo sobre as feminilidades, as normatizações/cristalizações de nossa sociedade.

Quando não se foge do binarismo ocorre à dominação masculina, tanto no espaço privado como no público, culminando em violências sobre as mulheres, 
dissidências sexuais e de gêneros, decorrentes dos privilégios sociais, culturais, materiais e subjetivos restritos aos homens. Desta forma, quem não se enquadra na ideia de masculino produzida pelas regulações da biopolítica e do biopoder, passam a ser associados à figura feminina, passiva e dominada (WELZER-LANG, 2001).

Da mesma forma, a categoria de análise "gênero", quando pensada dentro do escopo de atuação da Psicologia, muitas vezes se mantém invisível, o que de certa forma faz com que sua dimensão subjetivadora não seja contemplada como elemento de constituição dos sujeitos. Entretanto acreditamos que os gêneros, como apresentados pelas teóricas citadas, se mostram como linhas de subjetivação primária das expressões dos desejos, que por sua vez, podem ajudar a Psicologia a problematizar os processos de subjetivações e as relações humanas contemporâneas.

Acreditamos que a Psicologia com um olhar ampliado e crítico pode ajudar na potencialização da vida desses sujeitos que estão presos, no entanto os psicólogos e as psicólogas devem estar empenhado(a)s na revisão de seus próprios valores e conceitos, e serem problematizadore(a)s junto com estes e com a sociedade sobre as vivências, seus direitos e desejos, ao contrário de uma Psicologia restrita a reducionismos diagnósticos, colocando estes sujeitos como sem "salvação" ou "coitadinhos"; com isso, acreditamos que a Psicologia estará contribuindo para que estes sujeitos (re)signifiquem discursos e ordens que os restringem o exercício da vida, de todas pessoas que estão aprisionadas às normas e cristalizações da sociedade. Apostamos em uma Psicologia implicada politicamente com a vida e a realidade dos sujeitos que estão no comércio de drogas ilícitas ou presos podendo se tornar um dos dispositivos de enfrentamento aos preconceitos e discriminações, sendo um dispositivo que os possa levar a ruptura e emancipação psicossocial, o que por sua vez promoveria a produção de relações humanas mais respeitosas e cidadãs.

\section{CONSIDERAÇÕES FINAIS}

A partir de revisão bibliográfica e nosso contato com os sentenciados por meio das entrevistas, cartografamos, como já apontado, que são diversas as linhas que compõem os sujeitos a entrarem no comércio de drogas ilícitas, assim como apontou Foucault (2010) quando coloca que são necessários diversos acasos para que um sujeito pratique um crime. Com isso, não podemos dar ênfase, apontar, ou sublinhar 
uma destas linhas, pois outras estariam sendo perdidas, esquecidas, largadas na marginalidade, assim como o Estado e parte da sociedade tende a fazer.

Em uma perspectiva crítica, encontramos a emergência da problematização no campo da Psicologia e em especial na temática da criminalização - de novos paradigmas, que se pautem na questão da pobreza, falta de empregos e políticas públicas, entre outros, que contribuem para a atuação dessas pessoas em atividades ilegais e em especial, neste trabalho, no comércio de drogas ilícitas, evidenciando a grande tessitura das linhas. Acreditamos que se devam ter olhares mais abertos, percebendo que se trata de sujeitos compostos como rizoma, que são diversos os atravessamentos que passaram e passam por eles até o momento que resolvem se envolver em uma atividade ilícita.

A própria Psicologia, e por extensão, outros saberes e práticas relacionadas com as problematizações a respeito da relação das pessoas que atuam em atividade ilícitas (em suas formações e práticas desenvolvidas) precisam urgentemente ser revistas, considerando que as tendências reducionistas pouco contribuem com as problematizações trazidas pelos sujeitos entrevistados. Acreditamos que é necessário um novo olhar da Psicologia para à área da criminalização e segurança pública, esquecendo sua visão patologizante e possibilitando uma análise aberta, sem querer achar culpadas ou culpados.

Desmistifica-se a ideia de que todos trabalhadores do comércio de drogas ilícitas (do dono da boca até o vendedor) são os "terroristas brasileiros", um olhar alimentado pela "mass media" e que sempre se atualiza no imaginário social. Propomos a ampliação desses olhares para as histórias de vidas destes sujeitos, não os colocando como coitados ou coitadas, mas que a desigual realidade social brasileira fique clara, assim como as normatizações de classes, gêneros, raças e cores que se tem em nossa sociedade e que participam da construção de desejos que inserem esses sujeitos aos contextos demarcados pelo comércio e outras atividades ilegais.

Da mesma forma, a categoria de análise de "gêneros", quando pensada dentro do escopo de atuação da Psicologia, muitas vezes se mantém invisível, o que de certa forma faz com que sua dimensão subjetivadora não seja contemplada como elemento de constituição dos sujeitos. Entretanto, acreditamos que as relações de gêneros se mostram como linhas de subjetivação primária das expressões dos desejos, que por sua vez, podem ajudar a Psicologia a problematizar os processos de subjetivações e 
as relações humanas contemporâneas. Podemos complementar que a utilização de gêneros, aqui em especial as masculinidades, como categoria importante de análises para pensar o motivo das pessoas realizarem atos infracionais (atuação no comércio de drogas), é muitas vezes deixada de lado, ignorando a construção subjetiva dos sujeitos e a importância desta para as experiências vividas por estes.

A Psicologia, com um olhar ampliado e crítico, pode ajudar na potencialização da vida desses sujeitos presos. Os psicólogos e as psicólogas devem estar empenhados na revisão de seus próprios valores e conceitos, problematizando sobre a vivência, direitos e desejos dos presos em conjunto com eles e a sociedade, ao contrário de uma Psicologia restrita à diagnósticos reducionistas, que colocam estes sujeitos como "sem salvação", rotulando-os como psicopatas, como no caso do estudo de Hilda Morana (2003) exemplo de uma ciência estigmatizante, sua tese em psiquiatria aponta ser possível através da "Escala Hare PCL-R Psychopathy Checklist Revised" diagnosticar a psicopatia (ligada a uma tendência geral ao cometimento de delitos) em pessoas que estão presas, através de uma entrevista semiestruturada. As respostas vão sendo pontuadas de zero a dois pontos, dependendo do grau de psicopatia apresentado. Com isso, a Psicologia estará contribuindo para que estes sujeitos (re)signifiquem discursos e ordens que os restringem a um universo limitado do exercício de suas vidas. Apostamos em uma profissão implicada politicamente com a vida e a realidade dos sujeitos que estão no comércio de drogas ilícitas ou presos, podendo se tornar um dos dispositivos de enfrentamento aos preconceitos e estereótipos, levando-os a ruptura e emancipação psicossocial, o que por sua vez promoveria a produção de relações humanas mais respeitosas e cidadãs.

Com essa pesquisa, esperamos estar contribuindo para que a Psicologia se alinhe ao seu tempo e se distancie de uma vez por todas de seu posicionamento limitado de que atos infracionais tenham suas causas em patologias, ou que é somente uma questão de desigualdade social; assim, entendemos que uma Psicologia com o olhar ampliado e significativo para estes sujeitos, pode contribuir para que muitos não atuem e outros não voltem para o comércio de drogas ilícitas.

Por fim, esta pesquisa nos proporcionou olhares repensados, de forma mais crítica e problematizadora em relação aos sujeitos presos e sujeitos que estão e/ou estavam no comércio de drogas ilícitas. Foi possível mapearmos diversas histórias de vidas, nas quais procuramos cartografar de forma crítica, baseados em um método cientifico, com um olhar humanizado, e aqui o humanizado se distancia dos 
reducionismos teóricos e os estereótipos que se cristalizam no imaginário social. Esperamos ter conseguido um trabalho científico problematizador sobre uma realidade que é apresentada pelos meios de comunicação com os olhares das vítimas (sociedade), se esquecendo de pensar nas outras pessoas, que também podem ser vítimas da sociedade e do Estado neoliberal.

Através dos olhares críticos e problematizadores, acreditamos que não se tem como achar culpados para o crescimento do comércio de drogas ilícitas e outros delitos, mas se deve problematizar a respeito de como se finda em um reducionismo quando "encontramos" um ou outro culpado (sejam as pessoas que estão atuando, as desigualdades, falta de políticas públicas, entre outros). 


\title{
GENDER RELATIONS AND THE SUBJECTS WHO HAS WORKED AND ARE STILL WORKING IN THE TRADE OF ILLICIT DRUGS
}

\begin{abstract}
:
This article discuss how gender relations and more specifically masculinities interfere in the subjects' engagement with illicit drugs trafficking. We have used the cartographic method to map the existential stories of eight people who were imprisoned, problematizing on their experiences until the moment that they were convicted by the article number 33 of the Brazilian Criminal Code. Based on the results of the cartographies it can be stated that there are multiple lines that interfere in the engagement in of some people into illicit drug trafficking. However gender relations have been highlighted by the subjects: the need to prove themselves as a "true man" was one of the most present factors in their speeches. Thus, we discuss the need of Psychology to distance itself from limited positions, for example, that criminal offenses have their causes in pathologies, or it is only a question of social inequality, we conclude it is more problematizing of the diverse lines that cross and construct the subjects.
\end{abstract}

Keywords: Social Psychology. Drug Trade. Masculinity. Juridical Psychology. Gender. Sexuality.

\section{LAS RELACIONES DE GÉNERO Y SUJETOS QUE ACTUABAN, ACTÚAN EN EL COMERCIO DE DROGAS ILÍCITAS}

\section{Resumen:}

Este artículo discute acerca de la interferencia de las relaciones de género, específicamente las masculinidades, en la busca de los sujetos por el comercio de drogas ilícitas. Utilizamos el método cartográfico para el mapeo de las historias existenciales de ocho personas que estaban detenidas, pensando sus experiencias de vida hasta la condenación por el art. 33 del Código Penal Brasileño. Con los resultados de las cartografías se puede presentar múltiples líneas que interfieren en el acceso al comercio de drogas, sin embargo, las relaciones de género se destacaron y la necesidad de probarse "hombre de verdad" fue uno de los factores más presentes en el discurso de los participantes. Por lo tanto, discutimos la necesidad de la Psicología distanciarse de posicionamientos limitados, por ejemplo, que las acciones de infracción tienen sus causas en patologías o solamente una cuestión de la desigualdad social, siendo más cuestionadora de las varias líneas que se cruzan y construyen los sujetos.

Palabras clave: Psicología Social. Comercio de Drogas. Masculinidad. Psicología Jurídica. Género Y Sexualidade. 


\section{REFERÊNCIAS}

BARCINSKI, M. Centralidade de gênero no processo de construção da identidade de mulheres envolvidas na rede do tráfico de drogas. Revista Ciência \& Saúde

Coletiva, v. 14, n. 5, 2009.

BERGERET, J. La violência fundamental: El inagotable Edipo. Madrid: Fondo de cultura Económica, Ortega, 1990.

BEAUVOIR, S. de. O segundo sexo. Rio de Janeiro: Nova Fronteira, 1980.

BORIS, G. D. J. B. Falas de homens: a construção da subjetividade masculina. São Paulo: Annablume, 2011.

BUTLER, J. Problema de gênero. Rio de Janeiro: Civilização Brasileira, 2003.

DE SOUZA, K. O. J. A pouca visibilidade da mulher brasileira no tráfico de drogas. Psicologia em estudo, v. 14, n. 4, 2009.

DELEUZE, G.; GUATTARI, F. Mil platôs: capitalismo e esquizofrenia, vol. 1. Rio de Janeiro, editora 34, 1995.

CONNEL, R. W. Políticas da masculinidade. Educação \& Realidade, v.20, n.02, p. 185-206, 1995.

DIAS, C. C. N. Da pulverização monopólio da violência: expansão e consolidação do Primeiro Comando da Capital (PCC) no sistema carcerário paulista. 2011. 386 f. Tese (Doutorado em Sociologia) - Faculdade de Filosofia, Letras e Ciências Humanas, Universidade de São Paulo, São Paulo, 2011.

FEFFERMANN, M. Vidas arriscadas: o cotidiano dos jovens trabalhadores do tráfico. Petrópolis: Vozes, 2006.

FIORELLI, J. O. ; MANGINI, R. C. R. Psicologia jurídica. São Paulo: Atlas, 2012.

FOUCAULT, M. História da sexualidade I: a vontade de saber. Rio de Janeiro: Graal, 1988. 
FOUCAULT, M. Vigiar e punir. Rio de Janeiro: Vozes, 1997.

FOUCAULT, M. Repensar a Política. Rio de Janeiro: Forense Universitária, 2010.

FREUD, S. Três ensaios sobre a teoria da sexualidade. Rio de Janeiro, Imago, 1996.

GARLAND, D. A cultura do controle: crime e ordem social na sociedade contemporânea. Rio de Janeiro, Revan, 2008.

KEHL, M. R. A mínima diferença: masculino e feminino na cultura. Rio de Janeiro: Imago, 1996.

LAURETIS, T. A tecnologia de gênero. In: HOLLANDA, H. B. de (Org.). Tendências e impasses. O feminismo como crítica da cultura. Rio de Janeiro: Rocco, 1994, p. $206-242$.

LEI No. 11.343. Institui o Sistema Nacional de Políticas Públicas sobre Drogas Sisnad; prescreve medidas para prevenção do uso indevido, atenção e reinserção social de usuários e dependentes de drogas; estabelece normas para repressão à produção não autorizada e ao tráfico ilícito de drogas; define crimes e dá outras providências. Brasília, DF: Presidência da Republica, 2006.

LIMA, C. B. de. Jovens em conflito com a lei: liberdade assistida e vidas interrompidas. Londrina, PR: EDUEL, 2009.

PACHECO, P. J. Sistema prisional: o que a psicologia tem a (se) ver com isso?. In: Neuza, M. F. et al. Psicologia, formação, política e produção em saúde. Porto Alegre: EDIPUCRS, 2010, p. 271 - 288.

PEDROSO, C. R. Os signos da opressão: história e violência nas prisões brasileiras. São Paulo: Arquivo do Estado, Imprensa Oficial do Estado, 2002.

PERES, W. S.; SANTOS, C. H. Tecnologias de gênero, masculinidades e aprisionamentos na execução penal. Revista Internacional Interdisciplinar INTERthesis, Florianópolis, v.08, n.01, 185-199, 2011.

ROCHA, L. C. da. A prisão dos pobres. 1994. 116 f. Tese (Doutorado em Psicologia) - Instituto de Psicologia, Universidade de São Paulo, São Paulo, 1994. 
SÁ, A. A. de. Criminologia clínica e psicologia criminal. São Paulo: Revista dos Tribunais, 2007.

SCOTT, J. Gênero: uma categoria útil de análise histórica. Educação \& Realidade, v. 20, p. 71-99, 1995.

SERAFIM, A. de P. Aspectos etiológicos do comportamento criminoso: parâmetros biológicos, psicológicos e sociais. In: RIGONATTI, S. P.; SERAFIM, A. de P.;

BARROS, E. L. de. Temas em psiquiatria forense e psicologia jurídica. São Paulo: Vetor, 2003.

TELLES, V. da S. A cidade nas fronteiras do legal e ilegal. Belo Horizonte: Argvmentvm, 2010.

VARELLA, D. Carcereiros. São Paulo: Companhia das Letras, 2012.

WELZER-LANG, D. A construção do masculino: dominação das mulheres e homofobia. Revista de Estudos Feministas, Florianópolis, v.09, n.02, p. 460-482, 2001. 